\title{
Public Health Interventions for Control of Malaria in the Population Living in the Terai Region of Nepal
}

\author{
Kiran Raj Awasthi, ${ }^{1}$ Kazeem Adefemi, ${ }^{2}$ Mamata Sherpa Awasthi, ${ }^{3}$ Binaya Chalise ${ }^{4}$ \\ ${ }^{1}$ Department of Epidemiology and Biostatistics, School of Public Health, Curtin University, Perth, Australia, \\ 2Department of Health Policy and Management, School of Public Health, Curtin University, Perth, Australia, \\ ${ }^{3}$ Janamaitri Institute of Health Sciences, Kathmandu, Nepal, ${ }^{4}$ Nepal Health Research Council, Ramshah \\ Path, Kathmandu, Nepal.
}

\begin{abstract}
Infectious diseases are a major problem for developing countries. Controlling and eradicating these diseases have remained a challenge because of the multitudes of social and environmental factors involved. However, a multi-sectoral and collective effort in dealing with these diseases has been shown to result in positive outcomes. This paper looks at the current situation of Malaria in Nepal and a population that is at high risk. It explains the impact that social and environmental determinants have on this target population. This review then critically examines the various possible public health interventions that could potentially help in the control of malaria in this high risk population, drawing from evidences and experiences reported from other countries with suggestions for adapting these interventions to the Nepali environment.

Keywords: Indoor residual spray; long lasting Insecticide nets; malaria, mass media campaign; public health interventions; terai; Nepal.
\end{abstract}

\section{INTRODUCTION}

Malaria is a common vector borne disease accounting for more than 23 million deaths worldwide. ${ }^{1}$ It remains one of the major causes of mortality in Sub Saharan Africa, Asia and Latin America. ${ }^{2,3}$ An estimated 2.8 million cases have been reported in India, alone which has increased the need for a joint effort to control this disease. ${ }^{4,5}$ With an estimated $70 \%$ of global population living in high malaria risk areas, there is always a threat of the disease reoccurring even in countries that have once successfully eradicated. ${ }^{6,7}$ The risk of resurgence could be attributed to factors such as population migration, disasters or conflicts, relatively weak control programs either due to lack of funds or a false sense of security in such places. ${ }^{3,8}$

A narrative literature review was thus conducted to critically assess the practicality of malaria control interventions from Nepal and other countries. Literatures were intensively searched in electronic databases such as Google Scholars, PubMed, ProQuest, Cochrane database of Systematic Review and the Curtin University library database. Combinations of key words (like malaria control, malaria transmission, vector born disease, public health intervention, effectiveness and prevention strategies) were used to access literatures published between 2000 and 2016. Reference list of available literatures were examined for additional relevant literatures. The authors also searched gray literatures and reports published by the Government and non-Government organizations of Nepal. Literatures published in language other than English were excluded from the review. The authors then maintained an EndNote (version X6) library to avoid duplication of the retrieved literatures. The authors read and reread the relevant literatures to extract the qualitative and quantitative information through note taking the major findings. This led the authors to narrate their findings under themes and sum themes as structured in his paper.

\section{MALARIA IN NEPAL}

Nepal has a population of 26.5 million out of which $70 \%$ live in malaria prone areas. ${ }^{9}$ Majority of these high-risk areas are the lowlands Terai of Nepal bordering India in the South. ${ }^{10,11}$ The Terai region is also the most densely populated area constituting of $50.27 \%$ of the total population. ${ }^{12}$ The government has listed 13 out of 75 districts as high-risk areas, while it is still an endemic in an additional 52 districts. ${ }^{10}$ There has been a considerable decrease in the number of malaria case reported over
DOI: http://dx.doi.org/10.3126/jnhrc. v15i3. 18837
Correspondence: Dr Kiran Raj Awasti, Department of Epidemiology and Biostatistics, School of Public Health, Curtin University, Perth, Australia. Email: oralhealth.hdsn@gmail.com, Phone: +9779851063678. 
the years. Statistics have shown a decrease in the number of malaria reports from an alarming 42,321 cases in 1985 to just 3,115 cases in $2010 .^{10}$ Contrary to the African scenario, three-fourth of the reported cases have been in people aged over 15 years with less than $1 \%$ affecting children below five years..$^{10,13}$ In this context, this paper examines public health interventions to decrease malaria in the population aged over fifteen years living in the high-risk 13 districts. It also focuses more on the lower and middle-income population.

\section{Review of Social and Environmental Factors}

Various social and environmental determinants play key roles in the malaria burden. Nepal is one of the poorest developing countries in the world with Gross Domestic Product (GDP) per capita (PPP) around $\$ 1200 .{ }^{10}$ Despite a decrease of $10 \%$ in the poverty levels between 1996 and 2004, there is still a marked difference between the rich and poor. ${ }^{14}$ Poverty influences disease burden by promoting hesitation to seek early treatment leading to late diagnosis and increased risk of mortality. ${ }^{15-17}$ Low household income makes buying protective nets unaffordable or even decreases its priority among expenses.

Moreover, with $83 \%$ of population living in rural areas with lack of road, employment opportunities, there is a growing problem of emigration. ${ }^{12}$ Migration has been further fueled by the ten-year Maoist insurgency in Nepal. ${ }^{18}$ Migration to India, a high malaria endemic area, for work, also increases the possibility of cross border spread. ${ }^{19,20}$ Increased urbanization in Terai means increase in construction sites leaving wet and damp areas, which act as breeding sites for mosquitoes. ${ }^{21,22} \mathrm{~A}$ majority of the houses in Terai are built with mud and thatched roofs with inadequate seal thus raising the risk of malaria. ${ }^{23}$

With a fertile and flat landscape, the Terai is regarded as the capital of agriculture. A large area of wetlands for agriculture near settlements, in addition to the long working hours of farmers in the fields without protective clothing, leaves them susceptible to mosquito bites. ${ }^{24}$ Around $25 \%$ of males and $43 \%$ of females in Nepal are illiterate. ${ }^{12}$ It has been well argued that increased literacy increases economic status and brings about awareness and ability to step beyond the traditional and customary ways of dealing with a disease. ${ }^{25}$ Lack of education has always been major obstacle in getting people to change their knowledge, attitude and beliefs. There is still a persistent caste discrimination culture in the Terai region of Nepal where the lower caste population are often secluded and barred from their basic rights such as education and employment. ${ }^{26}$

Global warming has increased the risk of natural calamities such as flooding, increased temperature and humidity, which there by further increases the risk of vector borne diseases. ${ }^{27-30}$ To avoid the extreme heat reaching nearly 43 degrees Celsius during monsoon season, most of the male population in Terai sleeps outdoors without protective nettings. Floods are common every year in the Terai because of its low lands. Lack of drainage and toilet facilities have left stagnant pools of water near settlements. Majority (75\%) of the population living in Terai does not have a toilet in their house. ${ }^{12}$ The proximity of irrigation canals, artificial ponds, and farms near the Terai settlements act as reservoirs for mosquito breeding. ${ }^{31} \mathrm{All}$ these environmental factors increase the risk of malaria.

\section{ANALYSIS OF PUBLIC HEALTH INTERVENTIONS FOR MALARIA CONTROL \\ Insecticide Treated Nets (ITN) and Long Lasting Insecticidal Nets (LLIN)}

Evidences support the contention that major decline in malaria is attributed to ITNs and LLINs. The ITNs are conventional mosquito nets that are treated with insecticides; mainly pyrethroids or non-pyrethroids, while the LLINs are manufactured in factories with $2 \%$ permethrin impregnated insecticides and remains effective even after 15 washings or for a period of more than three years. ${ }^{32}$ In Nepal, 1,209,320 LLINs were distributed freely by the government, with the support of international organisations, to the population in highrisk villages and to pregnant women visiting government institutions for antenatal care. ${ }^{10}$ There was significant decrease in the number of malaria cases during 20062010, when these nets were distributed. This indicates the effectiveness of the use of LLINS in decreasing malaria.

The use of ITNs and LLINs have been recommended by World Health Organisation as a major form of intervention to control malaria. There have been many studies to test the effectiveness of these insecticide treated nets. Studies have shown that treated nets are more effective in decreasing malaria than non-treated nets..$^{33,34}$ The per person cost of ITNs in India, which can be comparable to the cost in Nepal, is around US\$1.6, and since this cost is just a one off for a year or even for three years for LLIN it is not as expensive when compared to the mean cost per case averted which stands at US\$52. ${ }^{35}$ Evidences from 22 countries in Sub Saharan Africa have shown as much as $20 \%$ reductions of Anopheles flaviatilis with 
just the use of ITNs, thereby reducing child mortality by $23 \%{ }^{36}$ This is a significant result when considering the prevalence of the same species of mosquito spreading malaria in Nepal.

Some studies have reported how species like Anopheles gambiae and Anopheles funestus in Africa have started showing resistance to Pyrethroid treated ITNs. ${ }^{37}$ This is less of concern because of the paucity of the aforementioned species of Anopheles mosquitoes in Nepal. However, the issue of resistance raises some areas of concern as Indoor residual spraying (IRS) in Nepal primarily uses pyrethroids. Even reports on LLINs distributed in Kanchanpur districts indicated a decrease in efficacy of the nets by $60 \%$ after four washings, which require further investigation. ${ }^{10}$ The problem with LLINs in Nepal is the difficulty in reaching out to the whole population and the effect of user compliance on efficacy, which cannot be controlled.

\section{Indoor residual spraying (IRS)}

IRS intervention is aimed at decreasing the vector population with the use of insecticides such as dichlorodiphenyltrichloroethane (DDT), pyrethroids and non-pyrethroids compounds. ${ }^{38}$ IRS was one of the alternative interventions deployed by Nepal between 2004 and 2009 in several malaria risk areas where several forms of pyrethroids were sprayed biannually for five years in selected high-risk areas. Though this intervention resulted in a decrease of malaria transmitting Anopheles mosquitoes resulting in decreased malaria cases in some areas, a few places showed no significant changes. ${ }^{10}$ It was estimated that $13,501 \mathrm{~kg}$ of insecticide at a cost of US\$ 158,646 was used during the process with a coverage of over 116,856 houses in $2007 .{ }^{10}$ Indoor residual spraying costs US\$ 0.62 per person per year and US\$ 3.30 per household per year. ${ }^{39}$ There has been a considerable debate over the efficacy of IRS alone in decreasing the burden of malaria. IRS is regarded as a costly approach with possible health hazards but it has shown, at times, that it does indeed provide protection from malaria. ${ }^{38,40}$ IRS success stories with DDT date back as early as the Second World War when it was used successful in overcoming malaria. ${ }^{41}$ Studies in Mozambique and South Africa showed a resurgence of malaria during the 1980s and 1990s after Anopheline mosquitoes started showing resistance to IRS containing pyrethroids. ${ }^{42}$ The two countries reverted to DDT sprays and within six years of reintegration malaria was controlled. ${ }^{43} \mathrm{~A}$ study conducted in the island of Bioko showed a considerable decrease of Anopheles fluviatilis just after the first round of spray of pyrethroids while the resistant Anphoeles gambie mosquitoes were susceptible to carbamate containing
IRS. ${ }^{44}$ Similarly, decrease in the malaria cases was seen in Orissa, India after IRS using DDT. ${ }^{45}$ Cultural restrictions prevent IRS from being used inside houses, however, even sprays done in cowshed adjacent to the households also showed a significant effect on the number of mosquitoes. ${ }^{45}$ The cost of IRS per house per six months comes to an average of US\$2.2, which is significant compared to the cost it saves from treatment. ${ }^{42}$ India is also one of the largest producers of DDT in the world, which makes the product available and cheap in Nepal. ${ }^{41}$ The use of IRS could be a major intervention aimed at vector control in the Terai.

\section{Mass Media Campaign}

Lack of knowledge about the severity and cause of Malaria is still prevalent in many areas of Nepal. ${ }^{9,46}$ This inadequate knowledge is attributed to a large illiterate population. Nepal has not had a structured, comprehensive mass media campaign (MMC) as an intervention on malaria. For example, school curricula of Nepal, as well as the other parts of developing countries, do not adequately provides life skill information about malaria prevention such as the effective use of ITNs. ${ }^{47}$ Mass media aims to reach out to the population at risk through various promotive and preventive methods. It can be in the form of plays, songs, posters and pamphlets, street dramas and campaigns through the television or radio. These campaign aims at providing comprehensive knowledge about malaria and its prevention to the community at risk. ${ }^{48}$ Mass media is seen to reach out to even the culturally sensitive population in an effective way. This form of intervention is also feasible when dealing with a large population at an instant. The major aim of mass media is to bring about a change in behavior.

Mass media has been used for malaria prevention in many countries across the world. A campaign encouraging people to repair faulty bed nets through songs and posters proved a major success in Gambia. ${ }^{49}$ Generally, an illiterate population lack comprehensive knowledge on any disease, increasing the likelihood of severe complications. A study done in poor, less educated and marginalized population in Bangladesh showed that one third of the population had no knowledge on the mode of transmission of malaria. ${ }^{50}$ Similar strata in Nepal often revert to traditional healers for any form of treatment, which could be detrimental. Street dramas or puppet shows could be a way of imparting this knowledge in such a population. A similar intervention module used in Rajasthan in a predominantly illiterate population showed a positive change in knowledge and practices. ${ }^{51}$ The 'NightWatch platform' used in Cameroon, Senegal, Chad and Tanzania that combines 
Public Health Interventions for Control of Malaria in the Population Living in the Terai Region of Nepal

providing comprehensive knowledge on preventing malaria followed by regular reminder using celebrities and media such as radio and television has been a huge success. ${ }^{52}$ This campaign showed a significant increase in use of bed nets in Cameroon; from $30.6 \%$ to $52.3 \%$ among adults and from $41.1 \%$ to $65.4 \%$ among children under five years. ${ }^{52}$ Mass media campaigns require huge amount of funds from developing the campaigns to broadcasting it, which could be a constraint. However, a campaign through the female health care volunteers and local community members in Nepal, for instance, can decrease the cost significantly.

\section{RECOMMENDATIONS}

Each intervention has its own strengths in controlling malaria. A multi-sectoral and multi-dimensional approach using all three interventions collectively is required for proper malaria controls the Terai region. ITNs and IRS used together in many countries showed better results compared to only one intervention, by preventing mosquito bites and also controlling the vector population. ${ }^{53}$ Involvement of community groups, national and international agencies will be important to support the government in dealing with the high cost of the combined intervention. There is a definite need of using ITNs not just for the females and children sleeping indoors but also for a majority of male adult population sleeping outdoors in the Terai because the hot climate. Similarly, there is a periodic need for IRS in susceptible settlements adjoining cattle sheds, irrigation canals, and paddy fields. Mass media is necessary to provide knowledge to the uneducated and marginalized communities on malaria prevention and management. A constant reminder will help bring about a change in behavior. It is worthwhile piloting this combined intervention program design in two districts before scaling out to the other districts.

\section{CONCLUSIONS}

A lot of effort has been made to control the spread of malaria in Nepal. There has been some success in decreasing the disease burden to some extent. A constantly mobile population and the social and environmental factors associated with the disease make the process even more challenging. A lack of success in eradication could be attributed to the cost of interventions or the lack of motivation in the part of the population. A combined approach with IRS and change in attitude regarding the use of ITNs or LLNs through a mass media campaign could be the solution to this situation. However, there is a definite need for a collaborative effort starting from the community level to the policy level in dealing with this issue.

\section{REFERENCES}

1. Murray CJ, Rosenfeld LC, Lim SS, Andrews KG, Foreman KJ, Haring D, et al. Global malaria mortality between 1980 and 2010: a systematic analysis. The Lancet. 2012;379(9814):413-31. [Pub Med]

2. Kager PA. Malaria control: constraints and opportunities. Tropical Medicine and International Health. 2002;7(12):1042-6. [Full Text]

3. Stratton L, O’Neill MS, Kruk ME, Bell ML. The persistent problem of malaria: Addressing the fundamental causes of a global killer. Soc Sci Med. 2008;67(5):854-62. [마 Med]

4. World Health Organisation. World Health Statistics. Geneva: World Health Organisation, 2010.

5. Narayanasamy K, Chery L, Basu A, Duraisingh MT, Escalante A, Fowble J, et al. Malaria evolution in South Asia: knowledge for control and elimination. Acta Tropica. 2012;121(3):256-66. [Pub Med]

6. Gosling RD, Chandramohan D. Beware resurgence of malaria where incidence has fallen. BMJ. 2008;337:a1592.[Full Text]

7. Smith DL, Cohen JM, Chiyaka C, Johnston G, Gething PW, Gosling R, et al. A sticky situation: the unexpected stability of malaria elimination. Phil Trans R Soc B. 2013;368(1623):20120145.[Full Text]

8. Cohen JM, Smith DL, Cotter C, Ward A, Yamey G, Sabot OJ, et al. Malaria resurgence: a systematic review and assessment of its causes. Malar J. 2012;11(1):122. [다ll Text]

9. Joshi A, Banjara M. Malaria related knowledge, practices and behaviour of people in Nepal. J Vector Borne Dise. 2008;45(1):44. [Full Text]

10. Ministry of Health and Population. Nepal Malaria Strategic Plan 2011-2016. Kathmandu: Ministry of Health and Population, 2011. [PDF]

11. World Health Organisation. Nepal Malaria Programmem Review New Delhi India World Health Organization Regional Office for South-East Asia, 2011 Contract No.: SEA-MAL-265. [DF]

12. Central Bureau of Statistics. National Population and Housing Census 2011 Kathmandu: National Planning 
Commision, 2012. [PDF]

13. Ceesay SJ, Casals-Pascual C, Erskine J, Anya SE, Duah NO, Fulford AJ, et al. Changes in malaria indices between 1999 and 2007 in The Gambia: a retrospective analysis. The Lancet. 2008;372(9649):1545-54. [ Full Text]

14. Morey ER, Sharma VR, Mills A. Willingness to pay and determinants of choice for improved malaria treatment in rural Nepal. Soc Sci Med. 2003;57(1):155-65. [Pub Med]

15. Adler NE, Newman K. Socioeconomic disparities in health: pathways and policies. Health Affairs. 2002;21(2):60-76. [Full Text]

16. Marmot M. The influence of income on health: views of an epidemiologist. Health Affairs. 2002;21(2):31-46. [ [Full Text]

17. Furnée CA, Groot W, Pfann GA. Health and income: a meta-analysis to explore cross-country, gender and age differences. Eur J Pub Health. 2010:ckq166. [Full Text]

18. Do Q-T, Iyer L. Geography, poverty and conflict in Nepal. J Peace Res. 2010;47(6):735-48.

19. Prothero RM. Migration and malaria risk. Health, Risk \& Society. 2001;3(1):19-38.

20. Parajuli K, Ghimire P. Epidemiology of malaria in two Eastern districts of Nepal. KUMJ. 2010;8(1):45-50.[Full $\underline{\text { Text] }}$

21. Sampaio AMM, Kligerman DC, Júnior SF. Dengue, related to rubble and building construction in Brazil. Waste Management. 2009;29(11):2867-73.[Pub Med]

22. Maharjan S, Sigdel E, Sthapit B, Regmi B. Tharu community's perception on climate changes and their adaptive initiations to withstand its impacts in Western Terai of Nepal. Int NGO J. 2011;6(2);35-42. [ull Text]

23. Lindsay SW, Jawara M, Paine K, Pinder M, Walraven GE, Emerson PM. Changes in house design reduce exposure to malaria mosquitoes. Tropical Medicine \& International Health. 2003;8(6):512-7.[Full Text]

24. Koudou BG, Tano Y, Keiser J, Vounatsou P, Girardin O, Klero K, et al. Effect of agricultural activities on prevalence rates, and clinical and presumptive malaria episodes in central Côte d'Ivoire. Acta tropica. 2009;111(3):268-74. [Pub Med]

25. Dike N, Onwujekwe O, Ojukwu J, Ikeme A, Uzochukwu $\mathrm{B}$, Shu E. Influence of education and knowledge on perceptions and practices to control malaria in Southeast
Nigeria. Soc Sci Med. 2006;63(1):103-6. [Pub Med]

26. Stash S, Hannum E. Who goes to school? Educational stratification by gender, caste, and ethnicity in Nepal. Comp Educ Rev. 2001;45(3):354-78.

27. Githeko AK, Lindsay SW, Confalonieri UE, Patz JA. Climate change and vector-borne diseases: a regional analysis. Bull World Health Organ. 2000;78(9):1136-47. [Full Text]

28. Mills JN, Gage KL, Khan AS. Potential influence of climate change on vector-borne and zoonotic diseases: a review and proposed research plan. Environ Health Perspect. 2010;118(11):1507.[Pub Med]

29. Béguin A, Hales S, Rocklöv J, Åström C, Louis VR, Sauerborn R. The opposing effects of climate change and socio-economic development on the global distribution of malaria. Glob Environ Chang. 2011;21(4):1209-14.

30. Singh PK, Dhiman RC. Climate change and human health: Indian context. J Vector Borne Dis. 2012;49(2):55. [ㄹ Med]

31. Mishra SR, Dhimal M, Guinto RR, Adhikari B, Chu C. Threats to malaria elimination in the Himalayas. The Lancet Global Health. 2016;4(8):e519. [Full Text]

32. Sharma S, Upadhyay A, Haque M, Tyagi P, Mohanty S, Raghavendra K, et al. Field evaluation of Olyset nets: a long-lasting insecticidal net against malaria vectors Anopheles culicifacies and Anopheles fluviatilis in a hyperendemic tribal area of Orissa, India. J Med Entomol. 2009;46(2):342-50. [Full Text]

33. Lengeler C. Insecticide-treated bed nets and curtains for preventing malaria. Cochrane Database Syst Rev. 2004;2(2). [Full Text]

34. Gamble CL, Ekwaru JP, ter Kuile FO. Insecticide-treated nets for preventing malaria in pregnancy. Cochrane Database Syst Rev.. 2006;2(CD003755). [Full Text]

35. Bhatia MR, Fox-Rushby J, Mills A. Cost-effectiveness of malaria control interventions when malaria mortality is low: insecticide-treated nets versus in-house residual spraying in India. Soc Sci Med. 2004;59(3):525-39. [uㅡ $\underline{\text { Med] }}$

36. Eisele TP, Steketee RW. African malaria control programs deliver ITNs and achieve what the clinical trials predicted. PLoS Med. 2011;8(9):e1001088. [ [Full Text]

37. N'Guessan R, CorbelV, Akogbéto M, Rowland M. Reduced efficacy of insecticide-treated nets and indoor residual 
spraying for malaria control in pyrethroid resistance area, Benin. Emerg Infect Diseases. 2007;13(2):199-206.

38. Pluess B, Tanser FC, Lengeler C, Sharp BL. Indoor residual spraying for preventing malaria. Cochrane Database Syst Rev. 2010;2(CD006657). [ [Full Text]

39. GC PS, Pokharel P. Cost analysis of insecticide spraying for malaria control in a Terai district of eastern Nepal. Health Renaissance. 2016;12(3):175-9. [ Full Text]

40. Curtis CF, Mnzava AE. Comparison of house spraying and insecticide-treated nets for malaria control. Bull World Health Organ. 2000;78(12):1389-400. [Full Text]

41. Dalvie MA. DDT: Health Effects. In: Nriagu JO, Kacew S, Patz JA, Kawamoto T, Rennie DM, editors. Encyclopedia of Environmental Health Led. Burlington, Canada: Elsevier Inc; 2011. p. 6 - 10.

42. van den Berg H. Global status of DDT and its alternatives for use in vector control to prevent disease. Environ Health Perspect. 2009;117(11):1656. [ub Med]

43. Van Dyk JC, Bouwman H, Barnhoorn I, Bornman M. DDT contamination from indoor residual spraying for malaria control. Sci Total Environ. 2010;408(13):2745-52. [리 Med]

44. Sharp BL, Ridl FC, Govender D, Kuklinski J, Kleinschmidt I. Malaria vector control by indoor residual insecticide spraying on the tropical island of Bioko, Equatorial Guinea. Malar J. 2007;6(1):52. [Full Text]

45. Gunasekaran K, Sahu SS, Jambulingam P, Das PK. DDT indoor residual spray, still an effective tool to control Anopheles fluviatilis-transmitted Plasmodium falciparum malaria in India. Tropical Medicine \& International Health. 2005;10(2):160-8. [ [Full Text]
46. Regmi K, Kunwar A, Ortega L. A systematic review of knowledge, attitudes and beliefs about malaria among the South Asian population. IInfect Ecol Epidemiol. 2016;6. [Full Text]

47. Nonaka D, Jimba M, Mizoue T, Kobayashi J, Yasuoka J, Ayi I, et al. Content analysis of primary and secondary school textbooks regarding malaria control: a multi-country study. PLoS One. 2012;7(5):e36629. [ㅍll Text]

48. Koenker H, Keating J, Alilio M, Acosta A, Lynch M, Nafo-Traore F. Strategic roles for behaviour change communication in a changing malaria landscape. Malar J. 2014;13(1):1. [Full Text]

49. Panter-Brick C, Clarke SE, Lomas H, Pinder M, Lindsay SW. Culturally compelling strategies for behaviour change: a social ecology model and case study in malaria prevention. Soc Sci Med. 2006;62(11):2810-25.

50. Ahmed SM, Haque R, Haque U, Hossain A. Knowledge on the transmission, prevention and treatment of malaria among two endemic populations of Bangladesh and their health-seeking behaviour. Malar J. 2009;8(1):173. [피l Text]

51. Ghosh SK, Patil RR, Tiwari S, Dash AP. A communitybased health education programme for bio-environmental control of malaria through folk theatre (Kalajatha) in rural India. Malar J. 2006;5(1):123. [Full Text]

52. Bowen HL. Impact of a mass media campaign on bed net use in Cameroon. Malar J. 2013;12(1):36. [ull Text]

53. Kleinschmidt I, Torrez M, Schwabe C, Benavente L, Seocharan I, Jituboh D, et al. Factors influencing the effectiveness of malaria control in Bioko Island, equatorial Guinea. Am Journal Trop Med Hyg. 2007;76(6):1027-32. [Full Text] 